Correspondence

Richard Calderone calderor@georgetown.edu

Received 14 April 2004

Revised 2 July 2004

Accepted 14 July 2004

\section{Studies on the regulation of the two-component histidine kinase gene CHK1 in Candida albicans using the heterologous lac $Z$ reporter gene}

\author{
Dongmei Li, ${ }^{1}$ Valeria Gurkovska, ${ }^{1}$ Michael Sheridan, ${ }^{2}$ Richard Calderone ${ }^{1}$ \\ and Neeraj Chauhan ${ }^{1}$
}

${ }^{1}$ Department of Microbiology and Immunology, Georgetown University Medical Center, 312 SE Med. Dent. Building, 3900 Reservoir Rd, NW, Washington DC 20057, USA

${ }^{2}$ Department of Medicine, INOVA Fairfax Hospital, Fairfax, VA, USA

The two-component histidine kinase Chk1p of Candida albicans has been implicated in the regulation of cell wall biosynthesis. Deletion of CHK1 results in avirulence that in part may be due to the increased sensitivity of mutant strains to polymorphonuclear leukocytes. The mutant also does not adhere to human oesophageal tissue in vitro, probably as a consequence of its altered cell wall. In the current study, a CHK1 promoter-lacZ reporter (CHK1prlacZ) construct was expressed in wild-type C. albicans strain CAl4 and in two-component signal transduction mutants to determine the effect of environmental stress conditions on the regulation of $\mathrm{CHK1}$ and the co-regulatory activities among these proteins. It is shown that lacZ expression varied according to the type of growth conditions and incubation time; expression was also influenced by the strain background. lacZ expression in CAI4 was greater at $37^{\circ} \mathrm{C}$ and at a pH of 3.5 and in the presence of $4 \mathrm{mM} \mathrm{H}_{2} \mathrm{O}_{2}, 0.1 \mathrm{mM}$ menadione, $10 \%$ serum or $1.5 \mathrm{M} \mathrm{NaCl}$ compared to cells grown at 30 or $42^{\circ} \mathrm{C}$. The increases in expression were time-dependent and not observed until cells were incubated for $120 \mathrm{~min}$ in these conditions $(P<0 \cdot 05)$. As a correlate of the increase in transcription of CHK1-lacZ in the presence of $\mathrm{H}_{2} \mathrm{O}_{2}$, the chk1 mutant was more sensitive than wild-type and revertant cells to $\mathrm{H}_{2} \mathrm{O}_{2}$ in vitro. In addition to strain CAI4, we also measured CHK1p-lacZ reporter activity of mutants deleted in genes encoding other two-component proteins such as the response regulator gene SSK1, the histidine kinases, SLN1 and NIK1, and the HOG1 MAP kinase. Of these proteins, Ssk1p and $\mathrm{S} \ln 1 \mathrm{p}$ are presumed to mediate phosphotransfer to the HOG1 [hyperosmotic glycerol] MAP kinase pathway during oxidative and perhaps osmotic stress in C. albicans. Compared to strain CAI4, lacZ reporter activity increased significantly in the ssk1 mutant under all growth conditions after a 10 and 120 min incubation $(P<0 \cdot 0001)$. lac $Z$ expression in the ssk 1 mutant was less at $42{ }^{\circ} \mathrm{C}$ compared to all other growth conditions $(P<0.05)$. Furthermore, lac $Z$ reporter activity also increased in the hog 1 mutant of $C$. albicans. These data suggest that SSK1 and HOG1 indirectly or directly negatively regulate CHK1 under most growth conditions tested. In the $\sin 1$ mutant, downregulation of $C H K 1$ was observed in all growth conditions compared to strain CAI4 $(P<0.05)$, while regulation of lac $Z$ in the nik1 mutant was similar to strain CAl4 except when cells were incubated in the presence of $4 \mathrm{mM} \mathrm{H}_{2} \mathrm{O}_{2}$ for 120 min $(P<0.05)$. Western blot analysis was used to determine the role of Chk1p in phosphorylation of Hog $1 \mathrm{p}$ under oxidative or osmotic stress. It was found that Hog1p was phosphorylated in the chk1 mutant similar to wild-type CAF2-1 cells, although the temporal events of phosphorylation differed slightly in mutant cells. These results show that transcription of CHK1, as measured by the lac $Z$ reporter assay, is statistically increased when cells are exposed to several types of stress or when incubated in $10 \%$ serum in a mutant-specific background and at a specific time point. Of importance, our data also suggest that lac $Z$ expression is indirectly or directly regulated by the HOG1 MAP kinase pathway, although a determination of its position in this pathway or in a cross-talking pathway awaits additional studies. 


\section{INTRODUCTION}

Invasive candidiasis appears most often in the immunocompromised patient. The disease carries with it a high attributable mortality, due to at least two factors (Bodey et al., 1966; Wenzel, 1995). First, the infection often goes undetected and second, either therapy is started too late or drug failure occurs. While Candida albicans predominantly causes disease in debilitated patients, nevertheless, the organism expresses several virulence factors needed for its invasiveness and ability to colonize tissues. The expression of some of these virulence factors has been observed both in vitro and in vivo (Calderone \& Fonzi, 2001; NavarroGarcia et al., 2001). Signal transduction pathways that regulate virulence factor expression, such as morphogenesis, stress adaptation and cell wall biosynthesis, have been elucidated, but the upstream signalling events, such as the perception of environmental signals by receptors, are rather poorly characterized (Lengler et al., 2000).

Two-component signal transduction has been studied in both non-pathogenic and pathogenic fungi (Santos \& Shiozaki, 2001). Of interest, the absence of these proteins in mammalian cells offers some degree of specificity in the development of antifungal drugs (Barrett \& Hoch, 1998; Koretke et al., 2000). Two-component signal transduction proteins of C. albicans include three histidine kinases (Sln1p, Nik1p and Chk1p), two response regulator proteins (Ssk1p and $S k n 7 p)$ and a phosphohistidine intermediate protein (Ypd1p) (Calera \& Calderone, 1999b; Santos \& Shiozaki, 2001). Sln1p, Ypd1p and Ssk1p are probably orthologues of the HOG1 MAP kinase pathway proteins [hyperosmotic glycerol] that in Saccharomyces cerevisiae are used for the adaptation of cells to osmotic stress (Hohmann, 2002). In C. albicans these proteins have additional functions which include adaptation to oxidant stress, morphogenesis, virulence, adherence and cell wall biosynthesis (Alex et al., 1998; Alonso-Monge et al., 1999, 2003; Bernhardt et al., 2001; Calera et al., 1998, 1999, 2000a, b; Calera \& Calderone, 1999a; Chauhan et al., 2003; Kruppa et al., 2003, 2004b; Li et al., 2002; Nagahashi et al., 1998; Selitrennikoff et al., 2001; Singh et al., 2004; Srikantha et al., 1998; Torosantucci et al., 2002; Yamada-Okabe et al., 1999). All of the two-component genes except SKN7 have been implicated in the virulence of the organism in a haematogenously disseminated murine model. Deletions of $n i k 1$ or $\sin 1$ attenuate virulence, while deletion of chk1 abolishes virulence (Calera et al., 1999; Yamada-Okabe et al., 1999). Ssk1p, while not essential for adaptation to osmotic stress in C. albicans as it is in Saccharomyces cerevisiae, regulates adaptation to oxidant stress and the expression of cell wall proteins such as Als1p, Flo1p and Mnn4p (Chauhan et al., 2003). Downregulation of Als1p (Kapteyn et al., 2000) in the ssk1 mutant is offered as a partial explanation for the decreased adherence of the mutant to human oesophageal tissue in vitro (Li et al., 2002). Of the histidine kinases of C. albicans, Chk1p and Nik1p are not found in Sac. cerevisiae (Santos \& Shiozaki, 2001). Niklp of C. albicans, a homologue of Neurospora crassa nikl, is partially required for phenotypic switching and morphogenesis (Srikantha et al., 1998; Santos \& Shiozaki, 2001). In addition to C. albicans, a nikl orthologue has been reported in Aspergillus fumigatus (Pott et al., 2000).

Chk1p is homologous to the Mak2p and Mak3p of Schizosaccharomyces pombe. In that organism, these proteins are used for adaptation to oxidant stress (Buck et al., 2001). C. albicans strains deleted of $C H K 1$ have an altered cell wall phenotype characterized by a truncation of acid-stable cell wall mannan side chains, as well as a reduction in the amount of 1,3- $\beta$-glucan and an increase in the amount of 1,6- $\beta$-glucan (Kruppa et al., 2003). The primary lesion of the chk 1 null mutant has not been defined and is currently being investigated. That the mutant displays several changes in cell wall composition is often typical of fungal cell wall mutants. It would seem, therefore, that Chk1p is part of a signal pathway that regulates cell wall biosynthesis. The changes in cell wall composition may explain the reduced ability of the chk1 null mutant to adhere to human oesophageal tissue in vitro (Li et al., 2002).

While a presumed pathway similar to the HOG MAP kinase of Sac. cerevisiae is postulated in C. albicans that includes Sln $1 p$, Ypd1p and Ssk1p, the relationship of Chk1p to this pathway as well as with Niklp is unknown. To determine the relationship of Chk1p to the HOG1 MAP kinase and to the other histidine kinases, a CHK1 promoter-lacZ reporter construct was used to transform wild-type and the null mutants in $s s k 1, \sin 1$ and nik1 and measure expression of lac $Z$ under stress conditions and in serum. Furthermore, the relationship of Chklp to Hoglp was investigated by determining the phosphorylation of Hoglp using Western blotting in wild-type and the chk1 mutant as well as lacZ expression in the hog1 mutant of C. albicans.

\section{METHODS}

Strains and growth conditions. Candida albicans CAI4 and all other strains listed in Table 1 have been described previously and were used in transformations with the pChk1lacZ or pACT1prlacZ (pAU36) plasmids. Ura3 ${ }^{-}$clones from each mutant that were used for transformation were obtained by selection on $5^{\prime}$-fluoroorotic acid as described by Fonzi \& Irwin (1993). Strain CAI4 and all mutant strains were grown at $30^{\circ} \mathrm{C}$ in SD medium supplemented with uridine $\left(25 \mu \mathrm{g} \mathrm{ml}^{-1}\right)$. $\mathrm{Ura}^{+}$transformants were maintained and grown on SD medium without uridine. SD medium contains $2 \%$ glucose, $0.67 \%$ yeast nitrogen base without amino acids and $0 \cdot 12 \%$ of additional supplements. CAF2-1 was used in phosphorylation and oxidant sensitivity studies. It is $\mathrm{Ura3}^{+}$(Table 1).

Plasmid construction. Parent plasmid pAU36 has been described by Uhl \& Johnson (2001). It contains the lac $Z$ gene from Streptococcus thermophilus, which was codon-optimized for expression in C. albicans. The lacZ gene was placed under control of the ACT1 promoter of $C$. albicans and used to transform C. albicans

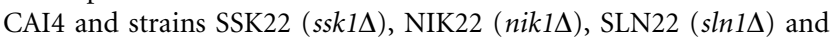
CNC15 $(h o g 1 \Delta)$ (Table 1), all of which are $\mathrm{Ura3}^{-}$. The plasmid pChkllacZ was constructed by amplifying a $1.4 \mathrm{~kb}$ fragment upstream of the start site of $C H K 1$ from CAI4 genomic DNA that was then used to replace a KpnI-SmaI fragment in pAU36 (Fig. 1a, top). The primers used to amplify the $1.4 \mathrm{~kb} C H K 1$ promoter were 
Table 1. Strains of C. albicans used in this study

\begin{tabular}{|c|c|c|}
\hline Strain & Genotype & Reference \\
\hline CAF2-1 & $\Delta u r a 3::$ imm434/URA3 & Fonzi \& Irwin (1993) \\
\hline SLN22 & 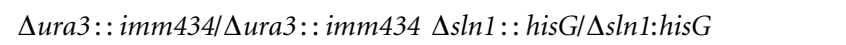 & This study \\
\hline NIK22 & 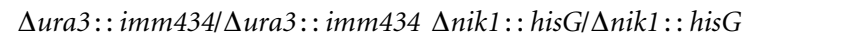 & This study \\
\hline CHK23 & 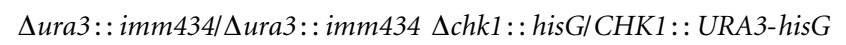 & Calera \& Calderone (1999a) \\
\hline
\end{tabular}

(a)

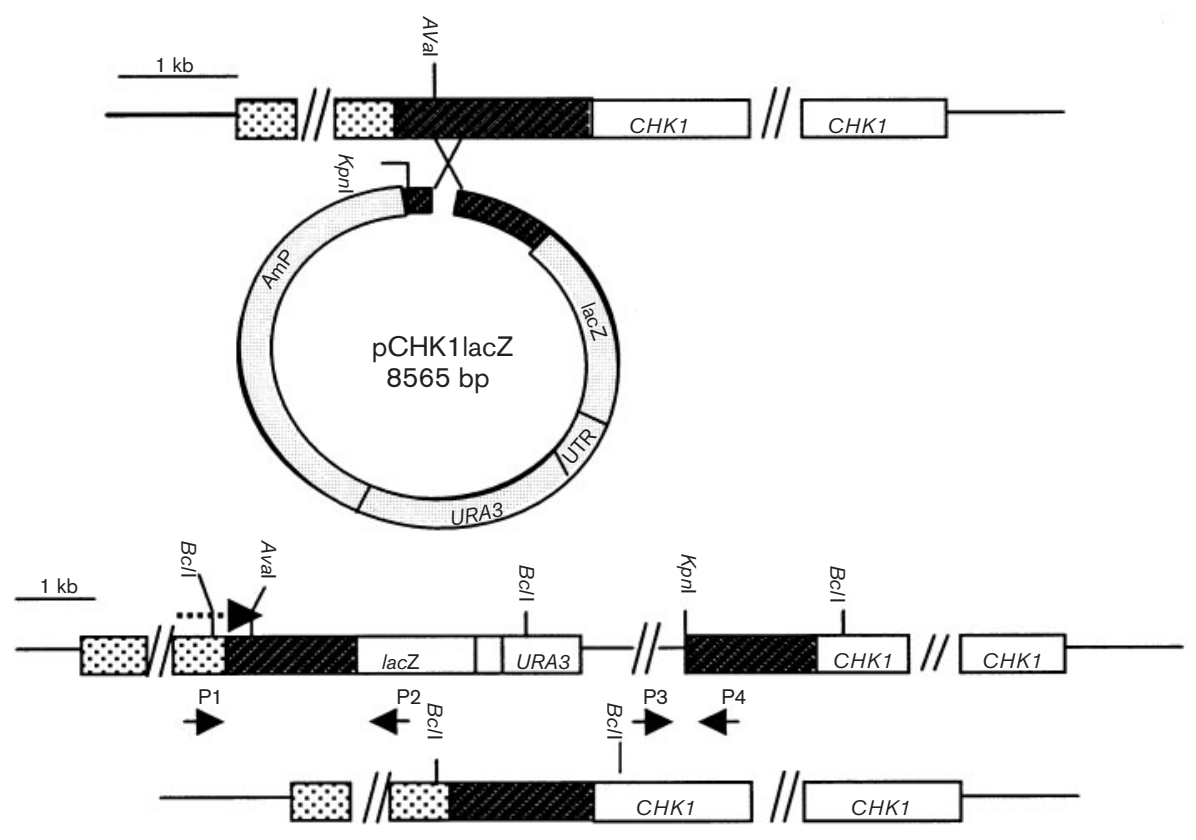

(b)

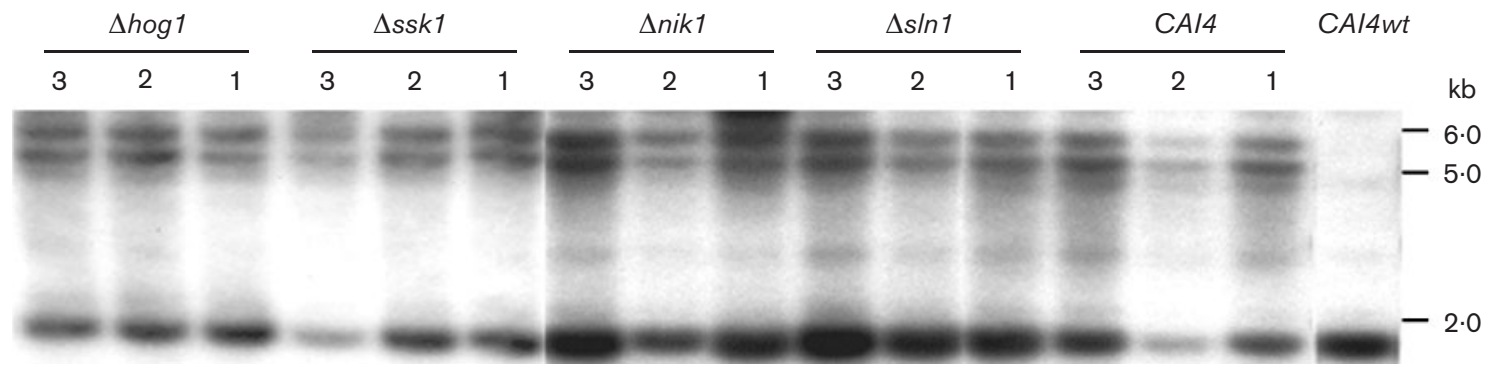

Fig. 1. (a) Top. Construction of the pChk1lacZ plasmid. The stippled (non-integrated) and dark (integrated) rectangles indicate the CHK1 promoter. The CHK1, URA3 and lacZ ORFs are indicated as clear rectangles. Middle. Restriction map of

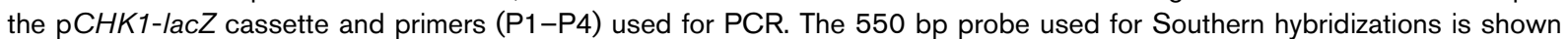
as a dotted arrow above the cassette. Bottom. The wild-type CHK1 allele is indicated with diagonal lines, indicating portions of the ORF. (b) Southern hybridizations of CHK1-lacZ transformants in CAl4 and the mutants described in Table 1. Genomic DNA from these strains was digested with $B c / l$ and hybridized with a 550 bp PCR fragment (indicated by a dotted arrow in Fig. 1a, middle). The lower band of approximately $1.84 \mathrm{~kb}$ is the wild-type allele of $\mathrm{CHK} 1$. Hybridizing fragments of approximately 4.9 and $5.6 \mathrm{~kb}$ are seen in each transformant. 
CHK5 (5'-AAATTCAAGGTACCCAATCAACTTTTCCAAG-3') and CHK3 (5'-CTGAAAAACTATTCTGTAAAAGGTCTGTACG-3'). The CHK1 promoter was ligated with the lacZ gene, including a $6 \mathrm{nt}$ plasmid sequence before the ATG start codon of lacZ.

Transformation. Transformation methods followed those of Calera \& Calderone (1999a). AvaI-linearized pChk1prlacZ (5 $\mu \mathrm{g})$ was used to transform CAI4 and each of the mutant strains (ssk1, nik1, sln1, hog1) using lithium acetate. Also, $5 \mu \mathrm{g}$ of the BtgI fragment obtained from linearized pAU36 that includes the ACT1 promoter sequence in-frame with lac $Z$ was introduced into CAI4 and the mutant strains to compare lacZ expression under the ACT1 and CHK1 promoters. Competent cells were obtained by growing each strain to early exponential phase in $50 \mathrm{ml} \mathrm{SD}$ medium containing uracil $\left(25 \mu \mathrm{g} \mathrm{ml}^{-1}\right)$. Cells were collected, washed twice with water and then resuspended in $0.1 \mathrm{M}$ lithium acetate with shaking at $30{ }^{\circ} \mathrm{C}$ for $1 \mathrm{~h}$. The volume of the suspension was reduced to $0.5 \mathrm{ml}$. AvaI-linearized pChklprlacZ $(5 \mu \mathrm{g})$ or BtgI-linearized pActlprlacZ $(5 \mu \mathrm{g})$ and $100 \mu \mathrm{g}$ denatured salmon sperm DNA were added to $100 \mu \mathrm{l}$ competent CAI4 or mutant strains and incubated at $30^{\circ} \mathrm{C}$ for $30 \mathrm{~min}$. A total of $0.6 \mathrm{ml} 40 \%$ PEG was added and the cell suspensions were incubated at $30{ }^{\circ} \mathrm{C}$ for $60 \mathrm{~min}$ and then heat-shocked at $42{ }^{\circ} \mathrm{C}$ for $5 \mathrm{~min}$. Transformants were centrifuged and plated on SD medium lacking uridine and cultured at $30^{\circ} \mathrm{C}$ for 2 days.

Southern hybridization and PCR. Verification of the correct integration of the CHK1prlacZ and Act1prlacZ cassettes in all transformants of CAI4 and mutants was accomplished by Southern hybridization using standard methods (Calera \& Calderone, 1999a). For the CHK1-lacZ transformants, genomic DNA from all strains was digested with $B c l$ I and probed with the $550 \mathrm{bp}$ fragment that is located at approximately $175 \mathrm{bp}$ upstream of the KpnI restriction site (Fig. 1a). For each transformant, two hybridizing bands of 4.9 and $5.6 \mathrm{~kb}$ were observed in Southern hybridizations (Fig. 1b). The ACT1-lacZ transformants were restriction-digested with HindIII and probed with an 800 bp sequence derived from the ACT1 promoter ( -1210 to $-410 \mathrm{bp}$, not shown). In addition to Southern analyses, two PCRs using primers P1-P4, indicated in Fig. 1(a), bottom, were also used to confirm the correct integration of each cassette mentioned above. First, a $1.79 \mathrm{~kb}$ fragment was amplified with primer CHK5' (5'-GACACCTCCTAATAACTCAC-3'), located at $\sim 80 \mathrm{bp}$ upstream of the $5^{\prime}$ end of the CHK1 promoter corresponding to the KpnI restriction site and an StlacZ3' primer ( $5^{\prime}$-TTCTTGAGGAACTTGAGGTG-3') at $\sim 200$ bp downstream of the lac $Z$ start codon (Fig. 1a, bottom, indicated as primer pair P1 and P2). The second PCR was performed using primers P3 (from pBSII KS + vector) and $\mathrm{P} 4$ (CHKpr3', 5'-CTCGGCGATACTCTACTAC-3') at about $350 \mathrm{bp}$ downstream of the KpnI site (Fig. 1a, bottom, primer pair P3 and P4). This PCR fragment was $387 \mathrm{bp}$ in size. Using the same strategy, ACT1-promoter-lacZ transformants were confirmed by two other PCRs. Primer ACT1pr5' (5'-GAGAGATTTGAAATGATCAG-3'), located at $\sim 198$ bp upstream of $5^{\prime}$ end of the ACT1 promoter-integrating site, and the StlacZ3' primer amplified a product of approximately $1.58 \mathrm{~kb}$ (data not shown). A second PCR utilizing the primers ACTpr3' (5'-TAGCACACACCCACAACAAC$\left.3^{\prime}\right), \sim 590$ bp downstream of the integrating site, and T3 resulted in a 617 bp PCR fragment (data not shown).

$\boldsymbol{\beta}$-Galactosidase assays. Three transformants of CAI4 and each mutant strain were chosen for determinations of $\beta$-galactosidase activity. Quantitative determinations of $\beta$-galactosidase activity were performed by measuring the hydrolysis of the substrate ONPG from broth cultures as described by Uhl \& Johnson (2001) using midexponential-phase cells obtained in the following manner. Fresh YNB medium $(5 \mathrm{ml})$ with or without uridine was inoculated with $100 \mu \mathrm{l}$ of an overnight culture of CAI4 or each transformant.
Cultures were incubated at $30{ }^{\circ} \mathrm{C}$ with vigorous shaking for $3 \mathrm{~h}$ to achieve an $\mathrm{OD}_{600}$ of approximately $0 \cdot 3$. Cultures were then supplemented with $4 \mathrm{mM} \mathrm{H} \mathrm{H}_{2} \mathrm{O}_{2}, 0 \cdot 1 \mathrm{mM}$ menadione $\left(\mathrm{ViK}_{3}\right)$ or $1.5 \mathrm{M} \mathrm{NaCl}$. With other cultures, cells were collected by centrifugation and resuspended in $10 \%$ serum or M199 medium at pH $3 \cdot 5$. All cultures were then incubated at $30{ }^{\circ} \mathrm{C}$. Control cultures consisted of cells without supplements and maintained at $30^{\circ} \mathrm{C}$ in YNB. For other assays, cultures were shifted to 37 or $42^{\circ} \mathrm{C}$ and expression was compared to cells grown at $30^{\circ} \mathrm{C}$. Cells incubated as described above under each condition were harvested at 10,30 60 or $120 \mathrm{~min}$ for lac $Z$ assays. The cells were collected and resuspended in $5 \mathrm{ml} \mathrm{Z}$ buffer ( $\mathrm{pH} 7 \cdot 0,0 \cdot 01 \mathrm{M}$ sodium phosphate, supplemented with $\mathrm{KCl}$, $\mathrm{MgSO}_{4}$ and $\beta$-mercaptoethanol) (Uhl \& Johnson, 2001). Then, triplicate samples of cells $(0.8 \mathrm{ml}$ per strain and for each growth condition) were permeabilized with $25 \mu \mathrm{l}$ chloroform and $25 \mu \mathrm{l} 0 \cdot 1 \%$ SDS. Cells were equilibrated at $37^{\circ} \mathrm{C}$ for $5 \mathrm{~min}, 0 \cdot 2 \mathrm{ml}\left(4 \mathrm{mg} \mathrm{ml}^{-1}\right)$ of the ONPG substrate was added and the cells were mixed and incubated at $37^{\circ} \mathrm{C}$ for $20 \mathrm{~min}$. The reactions were stopped by the addition of $0.5 \mathrm{ml} 1 \mathrm{M} \mathrm{Na}_{2} \mathrm{CO}_{3}$, cells were then centrifuged in a Sorvall Biofuge Pico for $5 \mathrm{~min}$ at 3000 r.p.m. and $A_{420}$ was determined for each reaction. The units of $\beta$-galactosidase activity were determined by the following equation:

$U=\frac{1000 \times A_{420}}{t \times v \times \mathrm{OD}_{600}}$

where $t$ is time of reaction and $v$ is volume of culture used in assay.

Visual screens for C. albicans transformants were carried out by patching colonies onto X-Gal-modified medium (XMM) plates with $5 \mu \mathrm{l}\left(1 \times 10^{6}\right)$ mid-exponential-phase cells for each sample (Uhl \& Johnson, 2001). XMM contained $1.7 \mathrm{~g}$ yeast nitrogen base (without amino acids), $20 \mathrm{~g}$ glucose, $5 \mathrm{~g}$ ammonium sulfate and $20 \mathrm{~g}$ agar in $930 \mathrm{ml} \mathrm{H}_{2} \mathrm{O}$. After autoclaving, $70 \mathrm{ml} 1 \mathrm{M}$ potassium phosphate $(\mathrm{pH} 7 \cdot 0)$ and $2 \mathrm{ml} \mathrm{X-Gal}\left(20 \mathrm{mg} \mathrm{ml}^{-1}\right)$ solution were added.

Phosphorylation of Hog1p. The assay follows our protocol as described previously (Chauhan et al., 2003). The parental strain CAF2-1 and the chk1 null (CHK21) were grown in YPD medium supplemented with either $10 \mathrm{mM} \mathrm{H}_{2} \mathrm{O}_{2}$ or $1.5 \mathrm{M} \mathrm{NaCl}$ as described previously (Chauhan et al., 2003). At designated times following incubation $\left(t_{0}-t_{60} \mathrm{~min}\right)$, cells were collected, proteins extracted and equal amounts separated by SDS-PAGE. The electrophoresed proteins were then transferred to nylon membranes and first probed with a ScHoglp polyclonal antibody (anti-ScHog1; Santa Cruz Biotechnology). Subsequently, the blots were stripped and reacted with a phospho-p38 MAP kinase (Thr180/Tyr182) 28B10 mAb (anti-TGY $Y^{\mathrm{P}}$; Cell Signalling Technology Inc.). Blots were then developed as recommended by the manufacturer (Amersham Pharmacia Biotech).

In vitro sensitivity assays. To determine the sensitivity of the mutants to oxidant or osmotic stress, we used in vitro drop plate assays containing $2-10 \mathrm{mM} \mathrm{H}_{2} \mathrm{O}_{2}, 1-1 \cdot 5 \mathrm{M} \mathrm{NaCl}$ or $0 \cdot 1 \mathrm{mM}$ menadione in YPD agar (Chauhan et al., 2003). To these media, inocula of $50-5 \times 10^{5}$ yeast cells of CAF2-1, CHK21 (chk1/chk1), CHK23 (chk1/CHK1) and, for comparison, two other histidine kinases, the $\sin 1$ and nik1 mutants, were spotted onto the agar media. Plates then were incubated at $30^{\circ} \mathrm{C}$ for $48 \mathrm{~h}$ at which time growth was assessed at each cell concentration.

Statistical analysis. To determine the significance of lac $Z$ expression in different growth conditions or in strains, we used a nonparametric analysis-of-variance technique with multiple comparison tests (SAS 8.2, SAS Institute, Cary, NC, USA). All outcomes were considered statistically significant at $P<0 \cdot 05$. 


\section{RESULTS}

\section{Construction of C. albicans CHK1-lacZ reporter gene}

We used the Str. thermophilus lacZ gene in reporter assays with the $C H K 1$ promoter to determine the environmental signals that regulate transcription of $C H K 1$ in C. albicans wild-type cells (strain CAI4) as well as in strains that were deleted of other histidine kinase genes $(\sin 1, n i k 1)$, the response regulator gene (ssk1) or the hog1 MAP kinase mutant. These mutants were chosen for study to identify coregulatory activities of Chk1p and other two-component proteins as well as to determine if transcription of $\mathrm{CHK} 1$ was influenced by different environmental conditions. As an internal control, we used ACT1-promoter-lacZ that was also transformed into strain CAI4 and each mutant. Southern hybridization was used to ensure that the correct integration occurred with all transformants, but without the integration of tandem cassettes. BclI-digested DNA of untransformed as well as transformed CAI4 and mutants revealed a $1.84 \mathrm{~kb}$ fragment and in each mutant two hybridizing bands of 4.9 and $5.6 \mathrm{~kb}$ were observed (Fig. $1 \mathrm{~b}$ ) using the probe indicated in Methods. The ACT1-lacZ transformants were digested with HindIII and probed as described in Methods. Two hybridizing fragments of $5 \cdot 73$ and $5 \cdot 88 \mathrm{~kb}$ as well as a $3.5 \mathrm{~kb}$ fragment, the latter representing the wild-type allele, were observed. We also used PCR to verify the transformants in the background of each mutant strain and wildtype cells (CAI4). Primer set P1 and P2 amplified a $1.79 \mathrm{~kb}$ fragment, while a $350 \mathrm{bp}$ fragment was amplified by primer set P3 and P4 (data not shown).

\section{$\beta$-Galactosidase activity in CAl4 and mutant strains}

$\beta$-Galactosidase (CHK1-lacZ) activity in all strains was measured from cells grown in broth media (Fig. 2a, b). In addition, essentially similar results were obtained with the agar plate X-Gal agar assays (data not shown). The level of $\beta$ galactosidase in each strain indicated in Fig. 2 is expressed as absorption units for cultures that reached a similar optical density in each of the growth conditions described in Methods. For all determinations represented in Fig. 2(a-d), three clones of each transformant (mutants or CAI4) were assayed in triplicate and mean values for each of the three transformants are indicated. Experiments were repeated twice with similar results. We also measured the expression of ACT1-lacZ in mutant strains and CAI4 under all growth conditions to determine the changes in gene expression relative to CHK1-lacZ (data not shown). Thus, all data shown in Fig. 2(a-d) are normalized to the expression of ACT1-lacZ. Expression of ACT1-lacZ was similar for all strains under all growth conditions $(P=0 \cdot 76)$, although ACT1-lac $Z$ expression was higher in all strains when cells were incubated in $10 \%$ serum or $4 \mathrm{mM} \mathrm{H}_{2} \mathrm{O}_{2}(P<0 \cdot 05)$ (data not shown). We measured the temporal expression of lac $Z$ under all growth conditions and in each mutant at 0,10 , 30,60 and $120 \mathrm{~min}$ and found that for all strains, lacZ expression was highest after $10 \mathrm{~min}$ incubation. For comparisons among strains and under each environmental condition, we have included expression data in Fig. 2(a-d) from both 10 and 120 min. In Fig. 2(a), lacZ expression of CAI4 is compared to the $\sin 1$ and nik1 mutants. At $10 \mathrm{~min}$, the expression of lacZ in the $\sin 1$ mutant is lower than that of CAI4 under all growth conditions $(P<0 \cdot 05)$. However, expression of lacZ was not changed under any growth condition in CAI4 or either mutant. After 120 min under stress, expression of lac $Z$ varied according to the strain and environmental growth conditions (Fig. $2 \mathrm{~b}$ ). We observed that the expression of lac $Z$ in CAI4 increased when cells were grown in $0.1 \mathrm{M}$ menadione, $10 \%$ serum, $4 \mathrm{mM} \mathrm{H}_{2} \mathrm{O}_{2}$, $1.5 \mathrm{M} \mathrm{NaCl}$, pH $3 \cdot 5$, and at $37^{\circ} \mathrm{C}(P<0 \cdot 05)$. In the $\sin 1$ mutant, expression of lac $Z$ was lower than in CAI4, again under all growth conditions (Fig. 2b) $(P<0 \cdot 05)$. This observation indicates that $\operatorname{Sin} 1 \mathrm{p}$ positively affects lac $Z$ expression. On the other hand, lacZ expression in the nik1 mutant was similar to CAI4, except when cells were grown in the presence of $4 \mathrm{mM} \mathrm{H}_{2} \mathrm{O}_{2}$ or $1.5 \mathrm{M} \mathrm{NaCl}$ for $120 \mathrm{~min}$ (Fig. 2b) $(P<0 \cdot 05)$.

When compared to strain CAI4, we found that lacZ expression increased in the ssk 1 and hogl mutants under all growth conditions, including temperature, oxidants (peroxide and menadione), M-199 (pH 3.5), $10 \%$ serum and hyperosmotic stress $(1.5 \mathrm{M} \mathrm{NaCl})$ at $10 \mathrm{~min}$ (Fig. 2c) and 120 min (Fig. 2d) $(P<0.0001)$, but was significantly less when cells were incubated at 37 and $42^{\circ} \mathrm{C}$ than under all other growth conditions $(P<0 \cdot 05)$. The data in Fig. 2(c) and (d) indicate that SSK1 and HOG1 negatively regulate expression of CHK1.

\section{Phosphorylation of Hog1p in parental cells and the chk1 mutant}

The lacZ reporter assays indicated that Ssk1p, Hoglp and Sln $1 \mathrm{p}$ affect expression of CHK1-lacZ. To further define this interaction, we determined the phosphorylation of Hog $1 \mathrm{p}$ in both CAF2-1 and the chk1 mutant (strain CHK21), since Hoglp is a MAP kinase that is downstream of Sln $1 p$ and Ssk1p in Sac. cerevisiae and, presumably, C. albicans. Both strains were stressed with either $10 \mathrm{mM} \mathrm{H}_{2} \mathrm{O}_{2}$ or $1.5 \mathrm{M}$ $\mathrm{NaCl}$ and phosphorylation of Hoglp was measured. We knew from previous studies that Ssk1p is required for phosphorylation of Hoglp in cells under oxidant stress (Chauhan et al., 2003). In Fig. 3 (upper and lower panels), Hoglp is phosphorylated in CAF2-1 within 2 min after the shift to either stress condition. The phosphorylation signal then decreases by $60 \mathrm{~min}$. In strain CHK21 the temporal phosphorylation of Hoglp is somewhat different. Under oxidative stress, phosphorylation of Hoglp persists, even at $60 \mathrm{~min}$, while under osmotic stress, phosphorylation of Hoglp is delayed and a weak signal is first seen at $10 \mathrm{~min}$ which then persists for at least $60 \mathrm{~min}$. Thus, under both types of stress, Chk1p is not required for phosphorylation of Hoglp, although minimal temporal changes occur in the chkl mutant compared to wild-type cells. 

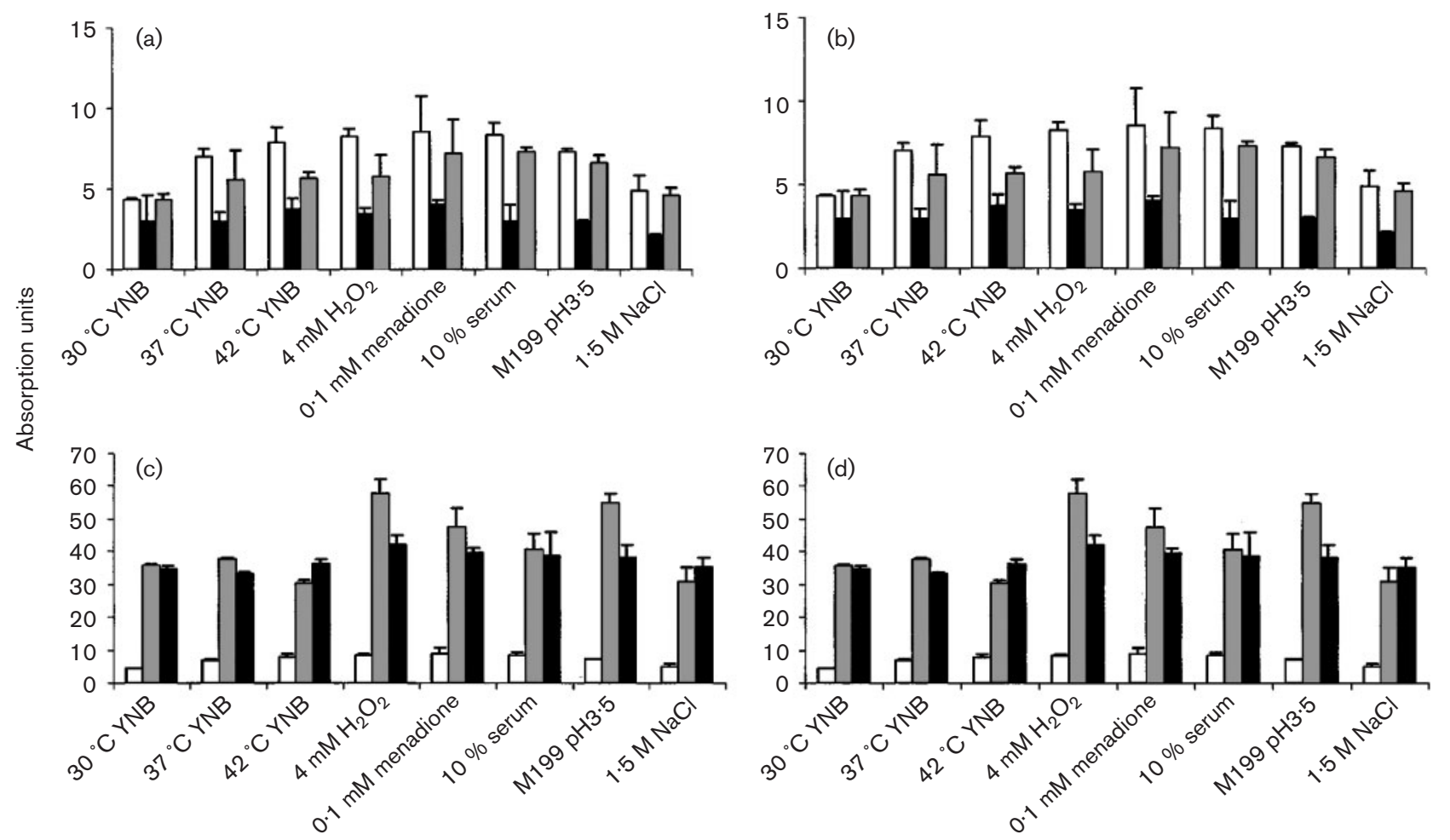

Fig. 2. $\beta$-Galactosidase activity in strains transformed with the CHK1p-lacZ cassette. CAl4 (white bars) is compared to the histidine kinase mutants $\sin 1$ (black bars) and nik1 (grey bars) after 10 (a) or 120 min (b) incubation under each of the conditions indicated. (c, d) lacZ expression in CAl4 (white bars) compared to the ssk1 (grey bars) and the hog 1 (black bars) mutants after 10 (c) or $120 \mathrm{~min}(\mathrm{~d})$ incubation. All strains were grown under the conditions indicated below each bar graph.

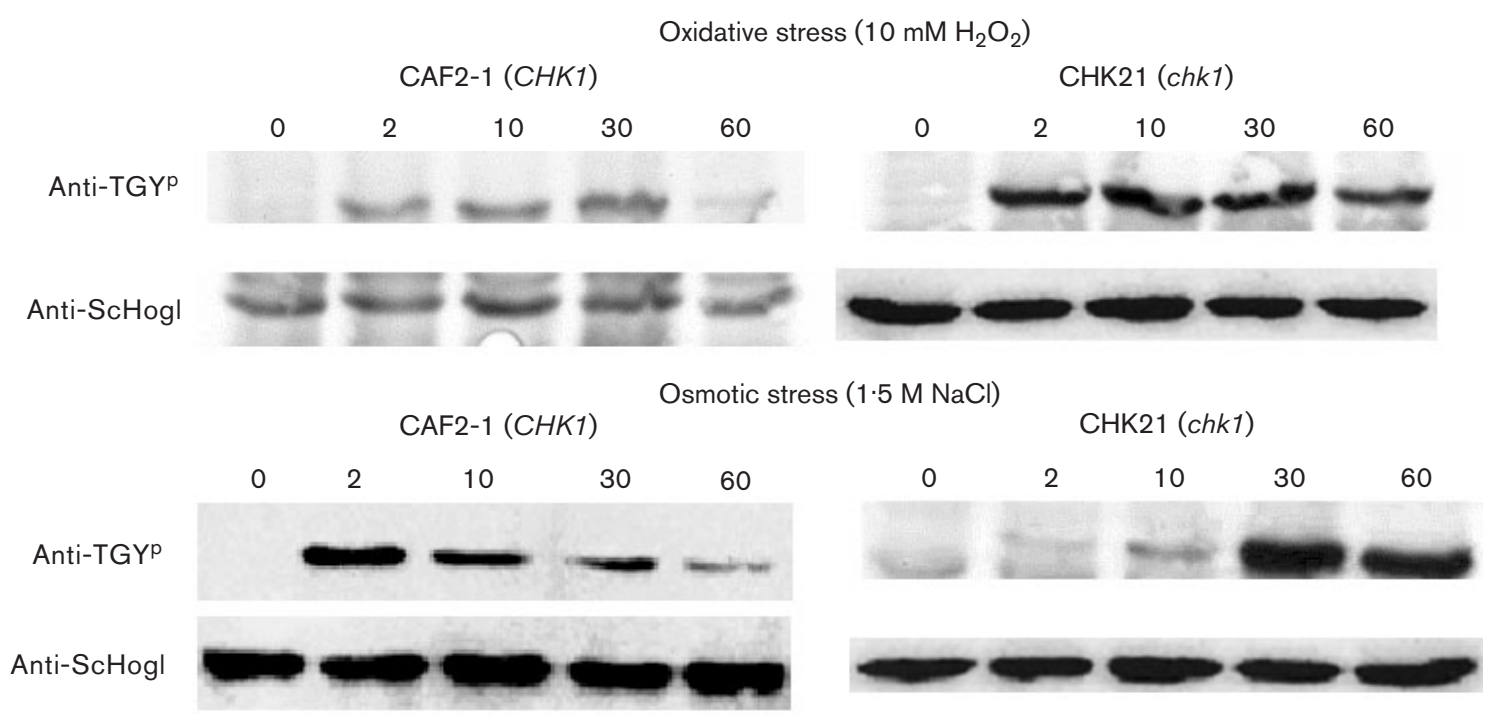

Fig. 3. Western blot analysis. Yeast cells of strains CAF2-1 and CHK21 (chk1/chk1) grown in YPD broth were collected, washed and shifted to YPD broth ( 0 time) containing $10 \mathrm{mM} \mathrm{H}_{2} \mathrm{O}_{2}$ (upper panels) or $1.5 \mathrm{M} \mathrm{NaCl}$ (lower panels) to induce oxidative or osmotic stress, respectively. At the times indicated above each lane ( $\mathrm{min}$ ), protein samples were obtained and Western blots were performed with an anti-Sac. cerevisiae Hog1p antibody (lower band, loading control). The blots were then stripped and reacted with an anti-TGY antibody (upper band) that recognizes the phosphorylated p38 protein of mammalian cells (Hog1p is a homologue of this protein). 


\section{Sensitivity of the chk1 mutant to oxidants and osmotic stress}

Drop plate assays were performed to determine the sensitivities of CAF2-1, the $\operatorname{chk} 1, \sin 1$ and nik1 mutants, and strain $\mathrm{CHK} 23$ (reconstituted with a single copy of CHK1) to $\mathrm{H}_{2} \mathrm{O}_{2}(2-10 \mathrm{mM}), \mathrm{NaCl}(1-1 \cdot 5 \mathrm{M})$ and $0 \cdot 1 \mathrm{mM}$ menadione. Concentrations above and below $4-5 \mathrm{mM}$ $\mathrm{H}_{2} \mathrm{O}_{2}$ were either too toxic or had no effect on the strains. Thus, we evaluated the sensitivities of each strain using different inocula concentrations $\left(5 \times 10^{5}-50\right.$ cells $)$ at $5 \mathrm{mM}$ $\mathrm{H}_{2} \mathrm{O}_{2}$ (Fig. 4). Of all the strains, the chk1 mutant (CHK21) exhibited the greatest sensitivity to $\mathrm{H}_{2} \mathrm{O}_{2}$. The $\sin 1$ mutant was similar in its sensitivity to CAF2-1 while the nik1 mutant was only slightly more resistant to peroxide than CHK21. The growth of all strains in $1.5 \mathrm{M} \mathrm{NaCl}$ or $0.1 \mathrm{mM}$ menadione, germination in $10 \%$ serum and growth at 30 , 37 or $42^{\circ} \mathrm{C}$, and in $\mathrm{M}-199, \mathrm{pH} 3 \cdot 5$, was similar to strain CAF2-1 (data not shown).

\section{DISCUSSION}

Reporter gene assays provide an approach to understanding the relationships among proteins. In C. albicans, several heterologous reporter genes have been used, including Kluyveromyces lactis LAC4 and Str. thermophilus lacZ (both reporters express $\beta$-galactosidase), Renilla reniformis luciferase, several versions of the green fluorescent protein and the Flp/FRT in vivo expression system (Leuker et al., 1992; Srikantha, 1996; Uhl \& Johnson, 2001). For a discussion of the advantages and disadvantages of each reporter system in C. albicans, readers are directed to the review by Berman \& Sudbery (2002). In this report, we used the lacZ gene of Str.

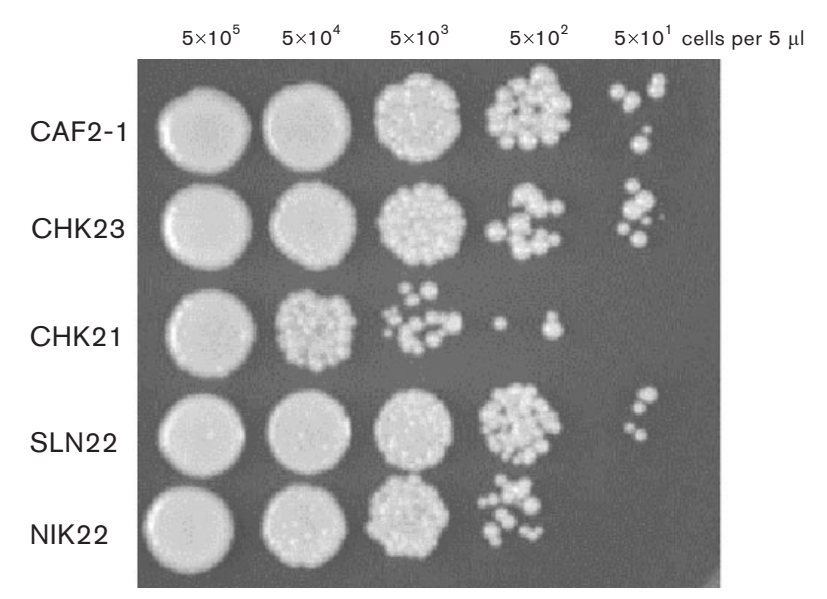

Fig. 4. Growth of CAF2-1 (wild-type), CHK23 (chk1/CHK1), CHK21 (chk1/chk1), SLN (s/n1/s/n1) and NIK (nik1/nik1) on YPD agar containing $5 \mathrm{mM} \mathrm{H}_{2} \mathrm{O}_{2}$ at $30^{\circ} \mathrm{C}$ for $48 \mathrm{~h}$. The medium was spotted with inocula ranging from $5 \times 10^{5}$ to 50 cells of each strain, in a volume of $5 \mu$ l. The plating efficiency was similar for all strains in the absence of peroxide. thermophilus as a reporter to identify regulatory interactions of Chk1p with other two-component proteins.

Chk1p is not found in Sac. cerevisiae, and while orthologues have been identified in Schizosaccharomyces pombe, Mak2p and Mak3p have not been assigned to a signal pathway (Buck et al., 2001). Based upon our current data, we postulate that the regulation of Chklp by proteins of the HOG1 MAP seems likely, but the alignment of Chk1p within or downstream of this pathway remains uncertain. Sln 1 p and Ssk1p are both components of the HOG1 pathway, yet their effects on Chklp transcription are opposite but reminiscent of their interactions in the Sac. cerevisiae HOG1 osmosensing pathway (Hohmann, 2002). In that organism, in unstressed cells, the downstream Ssk1p is inactive (unable to bind to the MAPKKK of the HOG1 pathway), because Ssk1p is phosphorylated by the phosphohistidine intermediate protein, Ypd1p, via the histidine kinase, membrane receptor protein $\operatorname{Sin} 1$ p. In osmotically stressed cells, Ssk1p is not phosphorylated and is able to activate the HOG1 MAP kinase pathway, which in turn results in an osmoadaptation. If SLN1 is deleted, then Ssk1p is constitutively active, since it is unphosphorylated in both stressed and unstressed cells; this leads to inviability in Sac. cerevisiae but not in C. albicans. Thus, in the C. albicans $\sin 1$ mutant, Ssk1p is presumably unphosphorylated and, hence, active, resulting in the downregulation of CHK1 transcription. Likewise, if SSK1 is deleted, then transcription of CHK1 increases. Support for the CHK1-lacZ expression profile in the $s s k 1$ mutant has been demonstrated in previous studies by microarray analysis, since $C H K 1$ transcription increases in the ssk 1 mutant (Chauhan et al., 2003). If this model of CHK1 regulation is correct, then Hog1p (downstream of Ssk1p) should likewise negatively regulate $C H K 1$. In fact, the hog1 deletion mutant behaves similarly to the ssk1 mutant: CHK1 transcription is increased. The effects of the SLN1 or SSK1 deletions on CHK1 in C. albicans are observed in both stressed and unstressed cells, but the level of expression of $C H K 1 p$-lac $Z$ is changed under some stress conditions at a specific time point.

We attempted to correlate the activity of Chk1p and Hoglp by Western blot analysis of phosphorylated and unphosphorylated Hoglp. Those data indicate that Chk1p is not required for Hoglp phosphorylation, although the deletion of $C H K 1$ caused a minimal temporal change in phosphorylation of Hoglp. These data suggest that Chklp is transcriptionally regulated but perhaps downstream of the HOG1 signal pathway.

The relationship of Nik1p to $C H K 1 p$-lacZ transcription is less apparent, since changes in the latter only occurred in a narrow range of growth conditions in the nikl mutant. From previous microarray data with the ssk 1 mutant, CHK1 transcription is increased, while NIK1 is unchanged compared to CAF2-1 (Chauhan et al., 2003). On the other hand, in the nik1, $\sin 1$ and $\operatorname{chk} 1$ mutants, the transcription profile of six mannosyl transferases increased similarly in each, and Western blotting profiles of acid-stable, but not 
acid-labile oligomannans were similar for each mutant (Kruppa et al., 2004b), implying that the three histidine kinases may have cross-talking interactions in regard to some common activities.

Chk1p of C. albicans, and for that matter all fungi that have two-component signal transduction, is a functionally novel histidine kinase in that it regulates cell wall biosynthesis. We have shown that the chkl mutant has profound changes in the composition of its cell wall, including levels of 1,3 - $\beta$-glucan (about $50 \%$ lower) and 1,6- $\beta$-glucan (about fourfold higher), as well as a truncation in the oligosaccharide side chains of the acid-stable mannan (Kruppa et al., 2003, 2004b). These changes have been confirmed by both biochemical and immunological determinations. Associated with the changes in cell wall structure is the reduced adherence of the mutant to human oesophageal tissues (Li et al., 2002; Bernhardt et al., 2001), increased sensitivity to human polymorphonucleocytes (Torosantucci et al., 2002) and avirulence (Calera et al., 1999). We now also show that the chk1 mutant is more sensitive to peroxide than parental cells in vitro using drop plate assays. More recently, Kruppa et al. (2004a) have demonstrated that Chk1p may be a receptor for quorum sensing caused by the autoinducer farnesol. The chk1 mutant is refractory to

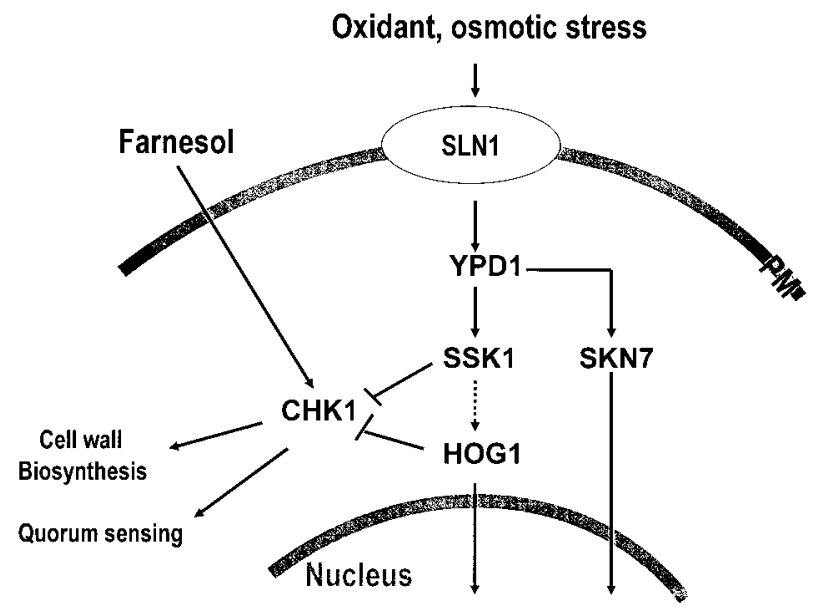

Fig. 5. Chk $1 p$ functions and its relationship to the HOG1 signal pathway of C. albicans. Hog1 is activated by either oxidant or osmotic stress via the $\operatorname{Sin} 1 p$ histidine kinase sensor protein. Both Ssk1p and Hog1p downregulate CHK1 transcription, while $S \ln 1 p$ upregulates transcription, since in the $\sin 1$ mutant Ssk1p is probably constituently active. On the other hand, the quorum sensing pathway which is induced by the isoprenoid farnesol is activated via Chk1p and does not require the HOG1 MAP kinase pathway (Kruppa et al., 2004b). Another major function of Chk1p is its regulatory activity in cell wall biosynthesis (Kruppa et al., 2003, 2004b). This activity is, like the farnesol pathway, independent of HOG1, since the ssk1 mutant does not exhibit the same cell wall phenotype as the chk1 mutant. Thus, Chk1p participates in at least three signal pathways. farnesol in comparison to wild-type cells and the $\sin 1, s s k 1$ and nik1 two-component mutants whose germination is inhibited by farnesol. This observation indicates a signalling pathway for Chk1p that does not include HOG1 twocomponent proteins. The Chk1p functions and relationship to the Hog1 pathway are summarized in Fig. 5. It appears that Chklp participates indirectly or directly in at least two signal pathways whose activation may depend upon the environmental signal, or Chklp may be downstream of Hoglp and transcriptionally regulated via the HOG1 MAP kinase pathway.

\section{ACKNOWLEDGEMENTS}

This study was supported by Public Health service Grants from the National Institute of Allergy and Infectious Disease, AI47047 and AI43465 to R. C. The authors also wish to thank Dr Alexander Johnson for providing plasmid pAU36 and Jesus Pla for contributing the hog 1 mutant (CNC15) of C. albicans. The authors also wish to thank Dr Mikio Arisawa of Nippon Roche for providing the $\sin 1$ and nik1 mutants. Fig. 5 was designed by Jean-Paul Debeaupuis of the Institut Pasteur, Paris, France.

\section{REFERENCES}

Alex, L. A., Korch, C., Selitrennikoff, C. P. \& Simon, M. I. (1998). COS1, a two-component histidine kinase that is involved in hyphal development in the opportunistic pathogen, Candida albicans. Proc Natl Acad Sci U S A 95, 7069-7073.

Alonso-Monge, R., Navarro-García, F., Molero, G., Diez-Orejas, R., Gustin, M., Pla, J., Sanchez, M. \& Nombela, C. (1999). Role of mitogen-activated protein kinase Hoglp in morphogenesis and virulence of Candida albicans. J Bacteriol 181, 3058-3068.

Alonso-Monge, R., Navarro-Garcia, F., Roman, E., Negredo, A., Eisman, B., Nombela, C. \& Pla, J. (2003). The Hog1 MAP kinase is essential in the oxidative stress response and chlamydospore formation in Candida albicans. Eukaryot Cell 2, 351-361.

Barrett, J. F. \& Hoch, J. (1998). Two-component signal transduction as a target for microbial anti-infective therapy. Antimicrob Agents Chemother 42, 1529-1536.

Berman, J. \& Sudbery, P. E. (2002). Candida albicans: a molecular revolution built on lessons from budding yeast. Nature Rev 3, 918-930.

Bernhardt, J., Herman, D., Sheridan, M. \& Calderone, R. A. (2001). Adherence and invasion studies of Candida albicans strains utilizing in vitro models of esophageal candidiasis. J Infect Dis 184, 1170-1175.

Bodey, G. P., Buckley, M., Sathe, Y. S. \& Freirch, E. J. (1966). Quantitative relationship between circulating leukocytes and infections in patients with acute leukemia. Ann Intern Med 64, 328-340.

Buck, V., Quinn, J., Pine, T., Martin, H., Saldanka, J., Makino, K., Morgan, B. \& Millar, J. B. A. (2001). Peroxide sensors for the fission yeast stress activated mitogen-activated kinase pathway. Mol Cell Biol 12, 407-419.

Calderone, R. A. \& Fonzi, W. A. (2001). Virulence factors of Candida albicans. Trends Microbiol 9, 327-335.

Calera, J. A. \& Calderone, R. A. (1999a). Flocculation of hyphae is associated with a deletion in the putative CaHK1 two-component histidine kinase gene from Candida albicans. Microbiology 145, 1431-1442. 
Calera, J. A. \& Calderone, R. A. (1999b). Histidine kinase, twocomponent signal transduction proteins of Candida albicans and the pathogenesis of candidosis. Mycoses 42, 49-53.

Calera, J. A., Cho, G. \& Calderone, R. A. (1998). Identification of a putative histidine kinase two-component phosphorelay gene (CaCHK1) in Candida albicans. Yeast 14, 665-674.

Calera, J. A., Zhao, X.-J., Sheridan, M. \& Calderone, R. A. (1999). Avirulence of Candida albicans CaHK1 mutants in a murine model of hematogenously disseminated candidiasis. Infect Immun 67, $4280-4284$.

Calera, J. A., Zhao, X.-J. \& Calderone, R. A. (2000a). Defective hyphal formation and avirulence caused by a deletion of the CSSK1 response regulator gene in Candida albicans. Infect Immun 68, 518-525.

Calera, J. A., Herman, D. \& Calderone, R. A. (2000b). Identification of YPD1, a gene of Candida albicans which encodes a two-component phospho-histidine intermediate protein. Yeast 16, 1053-1059.

Chauhan, N., Inglis, D., Roman, E., Pla, J., Li, D., Calera, J. \& Calderone, R. A. (2003). Candida albicans response regulator gene SSK1 regulates a subset of genes whose functions are associated with cell wall biosynthesis and adaptation to oxidative stress. Eukaryot Cell 2, 1018-1024.

Fonzi, W. A. \& Irwin, M. Y. (1993). Isogenic strain construction and gene mapping in Candida albicans. Genetics 134, 717-728.

Hohmann, S. (2002). Osmotic stress signaling and osmoadaptation in yeasts. Microbiol Mol Biol Rev 66, 300-372.

Kapteyn, J. C., Hoyer, L. L., Hecht, J. E., Muller, W. H., Andel, A., Verkleij, A. J., Makarow, M., Van den Ende, H. \& Klis, F. M. (2000). The cell wall architecture of Candida albicans wild-type cells and cell wall-deficient mutants. Mol Microbiol 35, 601-611.

Koretke, K. K., Lupas, A. N., Warren, P. V., Rosenberg, M. \& Brown, J. R. (2000). Evolution of two-component signal transduction. Mol Biol Evol 17, 1956-1970.

Kruppa, M., Goins, T., Cutler, J. E. \& 7 other authors (2003). The role of the Candida albicans histidine kinase (CHK1) gene in the regulation of cell wall mannan and glucan biosynthesis. FEMS Yeast Res 3, 289-299.

Kruppa, M., Krom, B., Chauhan, N., Bambach, A., Cihlar, R. \& Calderone, R. (2004a). The two-component signal transduction protein, Chklp, regulates quorum sensing in Candida albicans. Eukaryot Cell 3, 1062-1065.

Kruppa, M., Jabra-Rizk, M., Meiller, T. F. \& Calderone, R. A. (2004b). The histidine kinases of Candida albicans: regulation of cell wall mannan biosynthesis. FEMS Yeast Res 4, 409-416.

Lengler, K. B., Davidson, R. C., D'Souza, C., Harashima, T., Shen, W.-C., Wang, P., Pan, X., Waugh, M. \& Heitman, J. (2000). Signal transduction cascades regulating fungal development and virulence. Microbiol Mol Biol Rev 64, 746-785.
Leuker, C. E., Hahn, A. \& Ernst, J. F. (1992). $\beta$-Galactosidase of Kluyveromyces lactis (Lac4p) as reporter of gene expression in Candida albicans and C. tropicalis. Mol Gen Genet 235, 235-241.

Li, D., Bernhardt, J. \& Calderone, R. (2002). Temporal expression of the Candida albicans genes CHK1 and CSSK1, adherence and morphogenesis in a model of reconstituted human esophageal epithelial candidiasis. Infect Immun 70, 1558-1565.

Nagahashi, S., Mio, T., Ono, N., Yamada-Okabe, T., Arisawa, M., Bussey, H. \& Yamada-Okabe, H. (1998). Isolation of CaSLN1 and CaNIK1, the genes for osmosensing histidine kinase homologues, from the pathogenic fungus Candida albicans. Microbiology 144, $425-432$.

Navarro-Garcia, F., Sanchez, M., Nombela, C. \& Pla, J. (2001). Virulence genes in the pathogenic yeast Candida albicans. FEMS Microbiol Rev 25, 245-268.

Pott, G. B., Miller, T. K., Bartlett, J. A., Palas, J. S. \& Selitrennikoff, C. P. (2000). The isolation of FOS-1, a gene encoding a putative two-component histidine kinase from Aspergillus fumigatus. Fungal Genet Biol 31, 55-67.

Santos, J. L. \& Shiozaki, K. (2001). Fungal histidine kinases. Sci Stke 98, RE1.

Selitrennikoff, C. P., Alex, L., Miller, T. K., Clemons, K., Simon, M. I. \& Stevens, D. A. (2001). COS-1, a putative two-component histidine kinase of Candida albicans, is an in vivo virulence factor. Med Mycol 39, 69-75.

Singh, P., Chauhan, N., Ghosh, A., Dixon, F. \& Calderone, R. (2004). The SKN7 of Candida albicans: mutant construction and phenotype analysis. Infect Immun 72, 2390-2394.

Srikantha, T. (1996). The sea pansy Renilla reniformis luciferase serves as a sensitive bioluminescent reporter for differential gene expression in Candida albicans. J Bacteriol 178, 121-129.

Srikantha, T., Tsai, L., Daniels, K., Enger, L., Highley, K. \& Soll, D. R. (1998). The two-component hybrid kinase regulator CaNIK1 of Candida albicans. Microbiology 144, 2715-2729.

Torosantucci, A., Chiani, P., DeBernardis, F., Cassone, A., Calera, J. A. \& Calderone, R. A. (2002). Deletion of the two-component histidine kinase gene (CHK1) of Candida albicans contributes to enhanced growth inhibition and killing by human neutrophils in vitro. Infect Immun 70, 985-987.

Uhl, M. A. \& Johnson, A. D. (2001). Development of Streptococcus thermophilus lac $Z$ as a reporter gene for Candida albicans. Microbiology 147, 1189-1195.

Wenzel, R. P. (1995). Nosocomial candidiasis: risk factors and attributable mortality. Clin Infect Dis 20, 1531-1534.

Yamada-Okabe, T., Mio, T., Ono, N., Kashima, Y., Matsui, M., Arisawa, M. \& Yamada-Okabe, H. (1999). Roles of three histidine kinase genes in hyphal development and virulence of the pathogenic fungus, Candida albicans. J Bacteriol 181, $7243-7247$. 